\title{
A scoring system for sick children
}

\author{
M. A. OYEDIRAN, H. D. ZIEGLER, AND M. A. OJO
}

From the Department of Community Health, College of Medicine, University of Lagos, Nigeria

SUMmARY A scoring chart for sick children was designed using the vital signs of temperature, respiratory and pulse rates, and the central nervous system. The scoring chart was used on 68 sick children who had been randomly selected from a child welfare clinic in Lagos. Analyses of the charts showed that although values overlapped when related to clinical impression, there was an inverse correlation with the severity of the illness. The correlation coefficient between the doctors' and nurses' scores was high. Despite the need for further modification and investigation the scoring chart was promising as a screening tool for use by people who were not doctors and, possibly in some situations, by those who were not nurses.

Developing countries are continually experiencing problems because of their lack of medical manpower. Despite attempts to get more doctors from medical schools, the position does not appear to be improving. In an attempt to overcome the situation, various projects have shown that nurses can be used as nurse practitioners in both preventive and curative services. These services have particular application to mothers and children who constitute the most vulnerable groups.

One project which is involved in training and using nurse practitioners is run under the auspices of the Institute of Child Health of the University of Lagos. It was with the co-operation of the Institute of Child Health staff that this study took place. The purpose was to provide an easy means of identifying sick children who were in need of immediate medical treatment in child welfare clinics. It was hoped that such a method might reduce the responsibility of decision making for the harassed nurse or health worker. A scoring system was devised and tested preliminarily at the Shomolu Clinic in Lagos.

\section{Method}

The scoring chart was designed using the vital signs of temperature, respiratory rate and pulse rate, and a score related to the central nervous system. The temperature, respiration and pulse rates could be scored objectively, but the scoring for the central nervous system had to be made subjectively.

The form on which the scores were recorded is reproduced (Table 1). The highest score of 12 indicates a child who is well, while the lower the score the more severely ill is the child. The first objective was to determine if the sick child's scores correlated inversely with severity of illness. If this proved to be so, the second objective was to try to establish what scores should be attached to the different grades of severity of illness.

The ranges for the respiratory and cardiovascular systems were taken from textbooks (Bell et al., 1953; Nelson, 1959; Harvie, 1962). An attempt was made to average the values, especially for those children under one year of age, in order to give the most probable normal values. The values for the ill child were based on clinical judgement and experience.

Each vital sign was subdivided into age groups as shown. In the study, it was found that $82.4 \%$ of the patients were under one year of age, while $17.6 \%$ were between the ages of one and two.

The chart was tested at the Shomolu Clinic from 23 April to 29 May 1975 by a nurse practitioner and a doctor, each of whom used individual scoring charts for each child and performed the scoring independently of each other. The children were chosen at random from the clinic population. The doctor also made a clinical judgement as to the severity of the illness, which was independent of the score.

The charts were then analysed according to the following ages: 0-6 months, 7-12 months, and 13+ months. They were also analysed according to clinical impression which was rated as severely ill, moderately ill, and well or mildly ill.

The mean values and standard deviations for the scores were calculated. Spearman's correlation coefficient was calculated for the relationship 
Date

Family no.

Clinic no.

Name of patient

Age...

Years

Months

Sex

Condition at examination-Scoring chart:

1. Please tick in one box for each system examined.

2. Please record actual respiration and pulse rates in respective boxes.

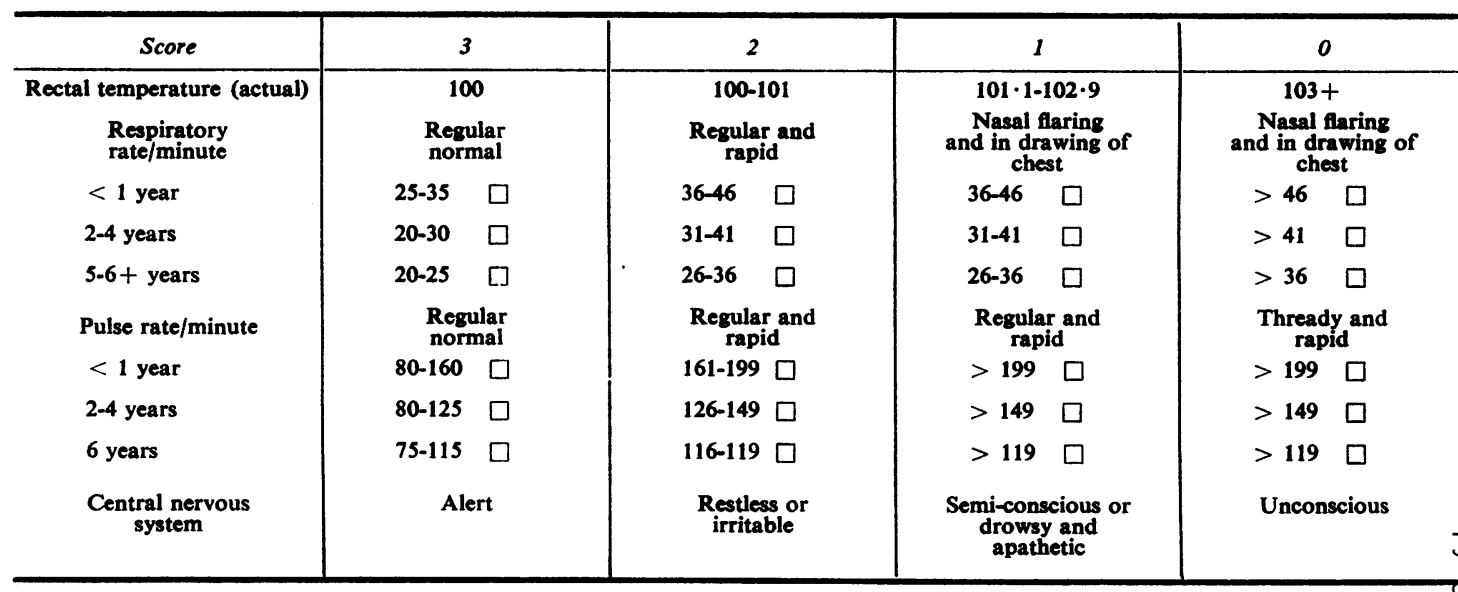

Scoring no. nurse

Scoring no. doctor

Diagnosis by doctor.

Clinical impression Well.

Mild.

Moderate.

Severe.

between the doctor's and the nurse's score. Pearson's correlation coefficient was calculated for the scores related to clinical impression.

\section{Results}

Table 2 shows that there was an overlapping of values for the scores related to clinical impression, and it would appear that these scores need to be narrowed so that they do not overlap.

To achieve a narrower range of scores, the central nervous system score was removed because it had been subjectively scored and it was in this that the greatest variations appeared. In Table 3, the results show that although the values for the scores related to clinical impression were much lower, there was still a degree of overlapping for the three ranges. The readings for the severely ill, the moderately ill, and the mildly ill or well were respectively $1 \cdot 78-5 \cdot 70,3 \cdot 12-9 \cdot 20$, and $6 \cdot 64$
Table 2 Score according to clinical impression

\begin{tabular}{|c|c|c|c|c|c|c|}
\hline \multirow{2}{*}{ Score } & \multicolumn{2}{|l|}{ Severe } & \multicolumn{2}{|c|}{ Moderate } & \multicolumn{2}{|c|}{ Mild/Well } \\
\hline & Nurse & Doctor & Nurse & Doctor & Nurse & Doctor \\
\hline $\begin{array}{c}1-2 \\
3-4 \\
5-6 \\
7-8 \\
9-10 \\
11-12\end{array}$ & $\begin{array}{l}1 \\
4 \\
6 \\
9 \\
4 \\
1\end{array}$ & $\begin{array}{r}2 \\
6 \\
10 \\
4 \\
3 \\
0\end{array}$ & $\begin{array}{r}0 \\
0 \\
1 \\
6 \\
16 \\
6\end{array}$ & $\begin{array}{r}0 \\
0 \\
1 \\
8 \\
16 \\
4\end{array}$ & $\begin{array}{l}0 \\
0 \\
0 \\
0 \\
5 \\
9\end{array}$ & $\begin{array}{r}0 \\
0 \\
0 \\
1 \\
3 \\
10\end{array}$ \\
\hline Total & 25 & 25 & 29 & 29 & 14 & 14 \\
\hline Mean & 6.06 & & $9 \cdot 19$ & & $10 \cdot 75$ & \\
\hline $\begin{array}{l}\text { Standard } \\
\text { deviation }\end{array}$ & 1.96 & & $1 \cdot 21$ & & 0.82 & \\
\hline $\begin{array}{l}\text { Spearman's } \\
\text { Pearson's }\end{array}$ & $\begin{array}{l}r 0.96 \\
\text { r } 0.98\end{array}$ & & 0.98 & & 0.93 & \\
\hline
\end{tabular}

8.82. In fact, there was a greater degree of overlapping than when the four variables were added together.

The correlation coefficient between the doctor's 
Table 3 Score (excluding that for central nervous system) related to clinical impression

\begin{tabular}{|c|c|c|c|c|c|c|}
\hline \multirow{2}{*}{ Score } & \multicolumn{2}{|l|}{ Severe } & \multicolumn{2}{|c|}{ Moderate } & \multicolumn{2}{|c|}{ Mild/Well } \\
\hline & Nurse & Doctor & Nurse & Doctor & Nurse & Doctor \\
\hline $\begin{array}{c}1-2 \\
3-4 \\
5-6 \\
7-8 \\
9-10 \\
11-12\end{array}$ & $\begin{array}{r}3 \\
11 \\
6 \\
3 \\
0 \\
0\end{array}$ & $\begin{array}{r}10 \\
8 \\
4 \\
1 \\
0 \\
0\end{array}$ & $\begin{array}{r}0 \\
2 \\
9 \\
14 \\
3 \\
0\end{array}$ & $\begin{array}{r}0 \\
4 \\
9 \\
12 \\
3 \\
0\end{array}$ & $\begin{array}{r}0 \\
0 \\
1 \\
12 \\
2 \\
0\end{array}$ & $\begin{array}{l}0 \\
0 \\
2 \\
8 \\
5 \\
0\end{array}$ \\
\hline Total & 23 & 23 & 28 & 28 & 15 & 15 \\
\hline Mean & $3 \cdot 74$ & & $6 \cdot 16$ & & $7 \cdot 83$ & \\
\hline $\begin{array}{l}\text { Standard } \\
\text { deviation }\end{array}$ & 1.96 & & $3 \cdot 04$ & & 0.99 & \\
\hline Spearman's & r 0.96 & & 0.99 & & 0.99 & \\
\hline
\end{tabular}

and the nurse's scores was high, ranging from 0.93 for mildly ill or well, to $\mathbf{0 . 9 8}$ for moderately ill, and 0.96 for severely ill (Table 2). This was also true when the scores were analysed according to age, as in Table 3. The correlation coefficients for the scores excluding the readings for the central nervous system were higher and were respectively 0.98 , 0.99 , and 0.96 . Pearson's correlation coefficient for the relationship between the scores and the clinical impression was also high.

Table 4 Score according to age

\begin{tabular}{|c|c|c|c|c|c|c|}
\hline \multirow{2}{*}{ Score } & \multicolumn{2}{|c|}{0.6 months } & \multicolumn{2}{|c|}{$7-12$ months } & \multicolumn{2}{|c|}{$13-24$ months } \\
\hline & Nurse & Doctor & Nurse & Doctor & Nurse & Doctor \\
\hline $\begin{array}{c}1-2 \\
3-4 \\
5-6 \\
7-8 \\
9-10 \\
11-12\end{array}$ & $\begin{array}{r}0 \\
0 \\
3 \\
4 \\
12 \\
9\end{array}$ & $\begin{array}{r}0 \\
3 \\
2 \\
6 \\
11 \\
6\end{array}$ & $\begin{array}{r}0 \\
3 \\
3 \\
6 \\
12 \\
4\end{array}$ & $\begin{array}{l}0 \\
3 \\
5 \\
6 \\
8 \\
6\end{array}$ & $\begin{array}{l}1 \\
1 \\
1 \\
5 \\
1 \\
3\end{array}$ & $\begin{array}{l}2 \\
0 \\
4 \\
1 \\
3 \\
2\end{array}$ \\
\hline Total & 28 & 28 & 28 & 28 & 12 & 12 \\
\hline Spearman's & r 0.96 & & r 0.98 & & r 0.90 & \\
\hline
\end{tabular}

The results demonstrate that the sick child's scores and the severity of illness are highly correlated in an inverse manner. On the average the scores were a valid indicator of severity of illness. However, the degree of overlap in the scores could limit their clinical usefulness.

\section{Discussion}

A scoring system was devised by Apgar and James (1962) and Apgar (1966) for use at specified intervals of time to predict the survival of neonates and to identify children at risk after birth. The Apgar score uses five signs to monitor the condition of neonates: heart rate, respiratory rate, muscle tone, reflex irritability, and colour. This scoring system has been found to be useful in identifying those newborn who are in need of immediate attention and it has been shown to have a significant association with neonatal mortality and infant morbidity (Drage and Berendes, 1966).

Unlike the Apgar score the sick child score of the current study does not incorporate a time factor. Also, no attempt has been made to use the score to predict survival of the child, although this could be incorporated in further studies. The main intention of the current study was to develop a scoring system that could identify the really ill child in a clinical setting to minimise delay before adequate and possibly specialised treatment is instituted.

As with the Apgar score the higher the sick child score the healthier or less severely ill is the child. Similarly, the observer of the Apgar score or the sick child score need not be a nurse or doctor as the observations involved are simple and can be performed routinely. This may be important as in some rural areas in developing countries the job of determining the severity of an illness in a child may rest with someone who is neither a doctor nor a nurse.

Even without further refinement, the sick child score is promising as a screening tool. If the three levels of illness are arbitrarily taken at the higher score to minimise the number of children considered mildly ill who are really seriously ill, the severely ill become anything under 8.0 . The moderately ill become anything over 8.0 but less than 11.0 . If this is done, nine of the 14 mildly ill or well children would be correctly identified. Twenty of the 25 severely ill children would be correctly labelled and would receive immediate attention. Sixteen of the 29 moderately ill children would be treated by the medical professionals after the severely ill had been seen, while only six would be incorrectly labelled as being mildly ill or well. In short, of 54 children who needed prompt professional attention, only seven would not have received it. This is an improvement on the system of patients being seen on a 'first come, first served' basis and is a more economical use of the doctor's or nurse practitioner's time. In many clinics most of the patients are well or mildly ill. If these results hold after further testing, approximately two-thirds of the well and mildly ill could easily be identified. They could then be seen by a dispensary assistant or, if there is time, by the doctor or nurse practitioner after the serious cases are seen.

The sick child's score would be even more useful if there were less overlap between the categories of severity of illness. One way to improve the precision of the score might be to narrow the physiological values and possibly divide the ages into smaller groups. These changes might reduce the overlap 
and allow a more precise assessment of the severity of illness.

Despite the fact that the mean values and standard deviation of the results showed some degree of overlap, it is felt that there is a possible role which the chart can fulfil in the decision making at infant and maternal welfare clinics. However, further investigations should be made.

We thank Professor O. Ransome-Kuti, Director of the Institute of Child Health, for his help and encouragement while the research was in progress and also Professor P. O. Fasan, Head of the Department of Community Health, for his help in analysing the results.

Reprints from: M. A. Oyediran, Department of Community Health, College of Medicine, University of Lagos, PMB 12003, Lagos, Nigeria.

\section{References}

Apgar, V. (1966). The newborn (Apgar) scoring system. Reflections and advice. Pediatric Clinics of North America, 13, 645-650.

Apgar, V., and James, L. S. (1962). Further observations on the newborn scoring system. American Journal of Diseases of Children, 104, 419-428.

Bell, G. H., Davidson, N. H., and Scarborough, H. (1953). In Textbook of Physiology and Biochemistry, 2nd edition, p. 503. Livingstone: London.

Drage, J. S., and Berendes, H. (1966). Apgar scores and outcome of the newborn. Pediatric Clinics of North America, 13, 637-643.

Harvie, F. H. (1962). In Paediatric Methods and Standards, 4th edition, p. 155. Kimpton: London.

Nelson, W. E. (1959). In Textbook of Paediatrics, 7th edition, p. 821. Saunders: London. 